\title{
PERSPECTIVES OF SPEECH-LANGUAGE PATHOLOGISTS ON THE USE OF TELEPRACTICE IN SCHOOLS: THE QUALITATIVE VIEW
}

\author{
JANICE K. TUCKER, SLP.D. \\ Speech language Support Programs, Lincoln intermediate Unit \#12, New Oxford, PA
}

\section{ABSTRACT}

Telepractice in speech-language pathology shows the potential to mitigate the current shortage of speech-language pathologists (SLPS) available to serve a growing number of persons with communication disorders. Since a majority of American Speech-Language-Hearing Association (ASHA) certified SLPs work in schools and the population of communicatively impaired clients in schools continues to grow, research into the use of telepractice in the educational setting is warranted. This article reports upon the perspectives of SLPs regarding the use of telepractice in school settings. In-depth qualitative interviews were conducted with five SLPs experienced in the delivery of telepractice. Four major themes emerged: barriers, benefits, reasons for acceptance and use of telepractice, and suggestions to resolve telepractice professional issues.

Keywords: Speech therapy, telepractice, schools

\section{INTRODUCTION}

This paper reports upon the qualitative portion of a larger mixed methods study that explores the perspectives of speech-language pathologists (SLPs) on the use of telepractice for school-based speech-language therapy.

It is American Speech-Language-Hearing Association's (ASHA's) position that telepractice is "an appropriate model of service delivery for the profession of speechlanguage pathology" (ASHA, 2005b, p.1). ASHA further states that telepractice may be used to overcome such barriers as patient distance to treatment locations, patient transportation difficulties, disruption of patient or family member work schedules, and limited availability of specialists and/or subspecialists in geographic regions (ASHA, 2005c). Telepractice shows potential to "extend clinical services to remote, rural, and underserved populations, and to culturally and linguistically diverse populations" (ASHA, 2005b, p. 1). However, telepractice is still in its infancy, and research into factors of benefits and barriers must be conducted.

In 2010, ASHA released a Professional Issues in Telepractice for Speech-Language Pathologists statement developed by the Ad Hoc Committee on Telepractice in Speech-Language Pathology, appointed in 2008 by the ASHA Board of Directors. The statement's intent was to clarify aspects of telepractice as a service delivery model, and to provide updates on quality of service, client practice, licensure and credentialing, and administrative support. The authors cautioned that this document was not a clinical guideline or an evidence-based systematic review. The report concluded with a call for continued research focused on the clinical and operational facets of telepractice, to include client, clinician, and caregiver satisfaction in experimental and real world settings (ASHA, 2010).

Communication disorders are among the most common type of disabilities in the United States. Of the over 6 million children (ages 3-21 years) with disabilities served in the public schools via the Individuals with Disabilities Education Act (IDEA) Part B in fall 2003, 24.1\% received services for speech or language disorders (Castrogiovanni, 2008). Additionally, 136,986 (2\%) received services for autism-related disorders. Although there is continued controversy concerning the incidence and prevalence of autism and autism spectrum disorders, there is no denying that the increasing number and severity of students with these diagnoses will heighten the need for school-based speech-language services (Schwartz \& Drager, 2008). Schwartz and Drager found that $82.8 \%$ of school-based SLPs regularly provide services to students on the autism spectrum. Medical advances that improve survival rates for infants who will later require speech-language assessment and treatment, along with the impact of earlier identification and services in early intervention settings (Bureau of Labor and Statistics, 2010), portend a continued demand for SLPs. 
There is a shortage of qualified SLPs to provide mandated special education services to a diverse, underserved, and expanding client base. According to the Bureau of Labor 2010-11 statistics from the U.S. Department of Labor, SLPs were employed in an estimated 119,000 jobs in 2008, and half of these were in preschool, elementary, and secondary school settings. Job opportunities are expected to be excellent over the next decade; a $19 \%$ increase is projected due to increased demand for speech-language services in most sectors of the population and an increase in the rate of retiring SLPs. The Bureau further reports that the SLP job outlook is very favorable for those who speak a second language or are willing to relocate to areas of the country that are experiencing difficulty hiring SLPs.

In many states, there are documented shortages of credentialed speech and language personnel to serve students in schools. For example, during the academic school year 2006-2007, the Pennsylvania Department of Education (PDE) issued 213 Emergency Instructional 1 certificates for Special Education: Speech and Language Impaired. By the 2008-2009 school year, this figure had climbed to 254 Emergency permits (Pennsylvania Department of Education, 2008). This shortage of qualified SLPs will not be ameliorated in the near future, and yet the clientele to be served continues to grow in size and diversity. Thus, the potential for telepractice in speech-language pathology to ease some of these barriers of personnel limitations and geographical distance must be considered. It is essential to include research on SLPS' knowledge, skills, experiences, attitudes, and beliefs concerning telepractice in speechlanguage pathology (ASHA, 2005b, 2005c; 2010; Polovoy, 2008), to examine the issues and circumstances affecting them, to address gaps in the literature on practitioners' telepractice perspectives, and to inform researchers and decision makers alike on important trends and impacts on future telepractice developments (ASHA, 2010; Mashima \& Doarn, 2008).

Telepractice technologies can provide wider access to speech-language pathology services by supplying skilled SLPs to rural and underserved populations, such as linguistically diverse clientele who require the services of bilingual professionals to meet their unique communication needs.

However, there remains limited knowledge about the outcomes and satisfaction levels of therapeutic speech interventions delivered in a distance format (Mashima \& Doarn, 2008). Research must be conducted to assure that service delivery via telepractice is of the same quality as that of traditional, face-to-face, speech therapy (ASHA, 2005b, 2005c).

Mashima and Doarn (2008) performed an extensive review of the telepractice literature, and concluded that systematic well-controlled randomized studies were scarce, and few studies included clinician viewpoints. Overall, the SLPs involved in telepractice reported positive perceptions after some initial skepticism. Mashima and Doarn caution, as does ASHA, that a critical factor for widespread acceptance and use of telehealth is clinician satisfaction (ASHA, 2005c, 2010; Mashima \& Doarn, 2008). These researchers also reported on a handful of studies in Australia, Ireland, United Kingdom, and the United States in which telehealth was used to reach remote locations and serve young children with speech and language disorders. These studies concluded that telehealth is a viable treatment option for young children both in homes and in schools. Mashima and Doarn recommended further research and articulated the need to develop standards and guidelines for telepractice.

Subsequent articles, such as those authored by Forducey (2006), Grogan-Johnson, et al. (2009), Juenger (2009a, 2009b), and Scheideman-Miller et al. (2002), support the use of telepractice in the school setting, but do not focus on SLPs' knowledge, attitudes, and beliefs. Currently, no surveys have been conducted on the topic of SLPs' current telepractice skills and perceptions concerning telepractice.

Knowledge of how SLPs perceive and even utilize telepractice in a speech-language pathology program could assist the profession in identifying ways to provide quality telepractice services to meet the needs of an increasingly diverse clientele (ASHA, 2005a, 2005b, 2005c). Information about problems encountered (and their solutions) may assist others who wish to use telepractice as a service delivery model for underserved populations. Schools, early intervention agencies, hospitals, and rehabilitation centers are all stakeholders in this process; each needs to learn how distance technologies can connect vulnerable children to services and curriculum in order to prevent social and/or academic failure. It is logical for these institutions to connect with the experts in the field (i.e., speech-language pathologists) to acquire best practices and identify the factors that will drive sustainability (Alverson et al., 2008; Dunkley, Pattie, Wilson \& McAllister, 2010).

This study was conducted to explore how telepractitioners perceive potential barriers such as the absence of in-person contact as well as the static nature of the treatment environment (ASHA, 2005b; Bulik, 2008). Additionally, the study attempted to augment the limited research in the area (ASHA, 2010; Dunkley et al., 2010; Whitten \& Holtz, 2008a, 2008b). 


\section{METHOD}

Qualitative interviews were conducted to explore the phenomenon of telepractice services from the perspectives of actual SLP providers and to answer the following questions:

1. What themes emerge from qualitative interviews about the implementation of school-based telepractice in speechlanguage pathology with SLPs who have experience with this form of service delivery?

2. What are the knowledge, skills, attitudes, and beliefs of SLPs with regard to the use of telepractice in the school environment?

The design of the interview instrument was based upon the barriers and challenges of telepractice described in the telemedicine, telerehabilitation, and telespeech literature, along with information from satisfaction and attitudinal surveys completed by SLPs in previous studies. The qualitative telephone interview consisted of 18 questions to explore SLPs' experiences, attitudes and beliefs regarding specific elements of telepractice. The first six items addressed years of experience as a SLP, and amount and type of telepractice experience. The next nine open-ended questions probed the participants' knowledge base, attitudes, beliefs, and perceived barriers to telepractice -- corresponding to themes identified from the literature search (ASHA, 2005b; Brennan \& Barker, 2007; Dunkley et al., 2010; Hjelm, 2005; Whitten \& Holtz, 2008b). The remaining three open-ended questions allowed for novel or unique responses in the hope of eliciting as of yet undiscovered themes or ideas that may guide future research (ASHA 2002, 2005a, 2010; Fink, 2003; Mashima \& Doarn, 2008; Scheideman-Miller et al., 2003).

To provide a measure of internal clarity and content validity (Creswell, 2008), the 18-item open-ended instrument was pilot tested via telephone or in-person discussion with ten SLPs. These participants were identified via mutual speech-language pathology contacts. Each participant had greater than 5 years of experience with school-based SLP practice. Minimal word order adjustments were made to the interview questions based on suggestions obtained from the pilot sample participants; the original core questions determined from the extensive literature review were retained. The piloting of the instrument, and subsequent revisions were completed within 2 weeks.

The researcher then contacted SLPs who were known to have at least 5 years of experience in the field and at least 4 months experience in the delivery of telepractice in speech-language pathology in school settings. These individuals were selected from a small pool of SLPs who were known to have experience with school-based telepractice services. The researcher did not personally know these SLPs but had been made aware of these individuals through mutual acquaintances. The researcher contacted the SLPs prior to the actual interviews to explain the purpose of the requested interview, to obtain written informed consent for permission to interview and transcribe the session, and to establish a convenient time for the telephone interview. Then, one-on-one open-ended telephone interviews were conducted by the researcher with the five SLPs who had provided telepractice services for the longest time periods. Each interviewee was advised of the confidentiality of her responses and reminded that their answers to the questions would be transcribed by the researcher for measures of accuracy and internal control (Creswell, 2008; Fink, 2003). The participants were assured before the interview that any quotes used in the research results would remain anonymous, and that their interview transcripts would not be shared.

Each interview lasted approximately 30 minutes. During the interviews, the researcher took detailed handwritten field notes and asked each interviewee to provide immediate feedback on any answer that the researcher felt was unclear or was unable to write the verbatim response. The interviews were then typed, with responses and quotes listed with every interview question, and sent to each individual participant within 48 hours for the reconciliation process. The reconciliation process allowed the interviewee an opportunity to review the content for any ambiguous or incorrect transcription and to validate that the researcher had perceived the true intent of the responses (Fink, 2003; Morton, Mullin \& Biemer, 2008). Each participant reviewed and returned the typed interviews with corrections or additions. The telephone interviews were completed within a 2-week time frame.

After the interviews were completed and reconciled, the researcher reviewed detailed notes of each interview to obtain an overall impression of the information and how it related to telepractice in school settings. Then, the researcher coded items with hand-written generalized labels by lines or paragraphs of the transcripts. The labels were read and reread and general themes were assigned from these notations. A code book was employed to list the codes and the definition of each code. The raw data was then reorganized by typing lines of text or quotes under the delineated codes. This cutting and sorting process from written transcripts was used to identify a priori (a deductive approach incorporating definitions from literature reviewed) and empirical data (an inductive approach) themes. These themes were further arranged by specific categories and/or subcategories reflective of similarity and frequency of responses (Bernard \& Ryan, 2010; Creswell \& Plano Clark, 2011). The resultant themes were reviewed with consideration of how they might contribute to the understanding of the SLPs' attitudes toward the use of telepractice in school settings.

As this data was sorted, extraneous data that did not answer any of the interview questions or relate to a theme or subtheme were not entered into the coded typed transcripts. Through this process, over 60 codes 
were developed which were synthesized across four broad themes. These resultant four themes were: telepractice barriers and telepractice benefits correlating with literature review, reasons for acceptance and use of telepractice, and suggestions toward resolving telepractice professional issues.

\section{PARTICIPANTS}

The qualitative research sample consisted of five ASHA certified SLPs who had at least 9 months of experience with telepractice in speech-language pathology in school settings, and more than 5 years of experience in the speech-language pathology field. Two of the SLPs went onsite to conduct standardized assessments and provided the telepractice from a school office; the others did not go onsite at any time, providing their telepractice services from their own homes or offices.

The inclusion of five participants was considered sufficient to gather a deeper and "information rich" (Creswell, 2003, p. 214) understanding of perspectives on telepractice service delivery in schools, and to discover emergent and consistent themes among this sample of responders. These individuals were excluded from the quantitative phase of the research to decrease the opportunity for bias (Creswell \& Plano Clark, 2011; Fink, 2003).

\section{RESULTS}

The first six interview questions dealt with speechlanguage pathology practice years, telepractice population, communication disorders served, and types of services provided. This data is outlined in Table 1, Summary of Qualitative Interview Questions 1-6.

The SLP's reported assessment procedures included informal measures, an online articulation test for initial sounds, and modified standardized tools (disclaimers were written to indicate the online adaptations of these tests).

The remaining questions, $7-18$, included the SLPs' experiences and perspectives regarding particular aspects of telepractice service delivery. Throughout this section, the use of quotation marks indicates direct quotes from the participants, while italics refer to the theme or subtheme terminology.
Table 1

Summary of Qualitative Interview Questions 1-6

\begin{tabular}{|l|l|}
\hline $\begin{array}{l}\text { No. yrs SLP } \\
\begin{array}{l}\text { Months/years } \\
\text { telepractice }\end{array}\end{array}$ & $11-36$ \\
$\begin{array}{l}\text { No.students } \\
\begin{array}{l}\text { Student population } \\
\text { served }\end{array}\end{array}$ & $\begin{array}{l}\text { Preschool - High School } \\
\text { (3 yrs - } 21 \text { yrs })\end{array}$ \\
$\begin{array}{l}\text { Communication } \\
\text { disorders served } \\
\text { A, F, L, LD, PDD, ASD, ELL, AAC, } \\
\text { CAPD, cleft palate }\end{array}$ \\
$\begin{array}{l}\text { Services provided } \\
\text { Screenings, assessments, IEP } \\
\text { meetings, therapy, consultations } \\
\text { with teachers, bilingual therapy }\end{array}$ \\
\hline
\end{tabular}

Note. $A=$ Articulation; $F=$ fluency/stuttering; $L=$ Language; $L D=$ Learning Disabled; PDD = Pervasive Developmental Disorder; $\mathrm{ASD}=$ Autism Spectrum Disorder; ELL = English Language Learner; AAC = Augmentative \& Alternative Communication; CAPD $=$ Central Auditory Processing Disorder

\section{TELEPRACTICE BARRIERS}

The literature currently discusses many barriers and limitations to telepractice implementation. The qualitative interviews sought to discover the challenges that actually occurred during telepractice in the school settings. The barrier most frequently mentioned was technology failure. All five participants had difficulty at some point and to some degree with the technology. Experiences included: no or interrupted Internet access; modem stopped working; computer crashed; no audio; microphones did not work; no video; frozen video connection/screen pictures; delays in sound transmission; a school that needed to be rewired to handle the technology; other "tech glitches"/technical problems for no apparent reasons; and no technical support.

Inadequate training, manifested by inadequate familiarity with the equipment and procedures, posed a significant barrier to telepractice service delivery. All five SLPs referenced a degree of prior training with the technology but no specialized or in-depth training. Their training varied from the opportunity to review the equipment with a teacher or another SLP, to some familiarization with basic computer technology and programs. One SLP did receive training on "the technology and programs, the game sets, and how to maneuver through technology aspects." Another SLP was provided time for work on basic computer skills and 
word processing. Two SLPs found "training on [their] own" through reading articles and talking to others in online chats. One SLP indicated that she did not learn the video recording processes. Other comments about training included: "none, it was baptism by fire!" and "it was trial and error for me to figure things out." They all found that using the technology while working with students was "different" and a challenge at first. Still, having adequate and dependable technology was the biggest challenge to overcome for any successful telepractice program rather than any specific training, according to all of these SLPS who used telepractice.

Barriers were encountered with telepractice delivery of sessions when untrained E-helpers or assistants could not set up the equipment properly; did not get the students to therapy on time; could not effectively manage student behavior; and did not have therapy materials ready. Able assistants, the SLPs added, knew the games, practice materials, and target therapy skills, and exercised good time management skills. Two of the respondents discussed the necessity of having an assistant (or someone else) close by to assure student safety. Thus, the challenges posed by deficits in training extended to assistants.

The lack of specified procedures to guide smooth and successful telepractice programming was the next most frequently cited barrier to telepractice. Without pre-established alternative and backup plans, the SLPS encountered a host of problems to solve by themselves. These included: malfunctioning computers and other hardware, Internet and electricity stoppages; dead air time; inability to see or hear students; inappropriate materials; distracted students; and perplexed helpers. The respondents felt that the lack of delineated procedures resulted in lost therapy time and confusion during sessions. These procedural needs were referred to as the "how to's" by one experienced SLP who provides training to new SLP telepractice providers. This individual commented that the SLPs want to know how the telepractice process works, (e.g., "how to manipulate the cameras," "how to stack lessons on the computer in the morning," and "how to move through activities so quickly."). Two other SLPs emphasized the importance of practicing beforehand by having "time to play around with things" such as the technology and equipment and to find available online tools and resources for appropriate use in telepractice sessions. SLPs new to telepractice need time to learn to operate the document camera so that picture cards or a manual can be shown. One individual stressed the importance of having a specific location used "only for teletherapy so that there is good resolution and sound."

Other procedural details noted as critical included the need to tell the students and others about the possibilities of technical or equipment failures, and to have procedures in place for when they occur, (e.g., when and how to make up or extend other sessions if students have missed therapy time). All pointed out that time will be needed "to put the program in place." Essential procedures involving the assistants were mentioned by two out of the five interviewees; since assistants are "that link to get materials home or to relay things to parents," and "always have someone there [or nearby] to intervene if needed." They recommended that training in technology and procedures should take place before beginning a telepractice program, and that training could be conducted onsite or over the phone for a duration of 30 minutes to approximately half a day.

The next theme, relative to the amount of responses generated, related to the barrier of the nature of the environment. Five of the interviewed SLPs discussed the static and distant elements of the online environment and how it affects the presentation of therapy via telepractice. The knowledge base of SLPs was the same, two commented, but it "was how it was translated that was the problem." These differences entailed learning to give more auditory and visual feedback to the students as to how things look and sound, and remembering to tell the students on the other side of the transmission if something was not working. A therapist indicated how she would think about feedback and have to adjust: [at] "times you think if I were there I would do this... and you can't." The SLPs discussed the static nature of the environment in terms of communication disorders, indicating that students with apraxia or Attention Deficit Hyperactivity (ADHD) "would be a challenge because we don't get the connection;" and "we are not right there." In summing up these challenges, one SLP advised that a critical characteristic for therapists who engage in telepractice is a "willingness to perform the same treatment tasks, but in a different format."

Also related to the nature of the environment was the challenge of a "time delay for speaking to one another because you stumble all over each other trying to talk and then can't hear each other." This SLP learned to speak and then "anticipate a response." She compensated by "talking before children finish what they are saying so it decreases the delay." She noted that "kids are not as affected by this as adults." Students can draw, type, or use Whiteboard for drawing, in lieu of sound. However, if a student "doesn't have strong typing skills [he] gets lost." Headsets were items that were either liked or disliked by the students and SLPs. Two SLPs were bothered by the headsets, so one learned to take them off between sessions. Another discussed how "students monkey with the headsets." This SLP likes to talk openly so everyone can hear, so she preferred that no one wore headsets. She pointed out that, "If you only have two headsets you can't talk to more people." Another SLP commented that being alone "in a cubicle all by myself," and at a distance from others was "a sterile environment; it was lonely;" "it was harder than I thought it would be." All five SLPs experienced a degree of adjustment to the ergonomics of the environment. While one found it lonesome, another found it exciting. Another discovered that it was 
exhausting because "you don't get up and walk down the hall very often."

The lack of physical contact with students was reported as a barrier to telepractice by four of the interviewees. Their individual comments state this barrier clearly: "lack of physical proximity is a challenge;" "to physically monitor a child's speech production was a challenge;" "the biggest challenge is that I can't touch the child if not creating the sound I want;" "still a struggle without physical redirections." Traditional articulation therapy techniques were difficult via telepractice at first. One specific example was explained in this manner, "if you could see more; or be there to use a tongue depressor; or with gloved hand move tongue; or use techniques [with food items] to work on /r/; this you can't do." Monitoring articulation from afar was difficult for both the student and the SLP. Telepractice made it more difficult to see what the tongue was doing for fine movements in sounds such as $/ r /$ One SLP remarked how she explained at length and drew pictures, but she could not use a tongue depressor to show the student exactly where the tongue should be placed. Also, physical redirection with very young children, such as hand over hand guidance, or showing and manipulating objects on a table "is very tricky" via telepractice.

Establishing therapeutic relationships constituted a barrier to overcome due, in part, to the differences encountered in establishing therapeutic rapport with students and other educators. Since the SLP could not be in the school building, it was not as easy to discuss the student with others or get a sense of the student's whole educational experience. Others were depended upon (e.g., the E-helper) to intervene if the student had behavior or attention problems, provide help in understanding home practice assignments, or get the student to therapy on time. SLPs found that they needed "good E-helpers." One description of this dilemma was "in brick and mortar schools you walk down the hall" to see if students are there, but in telepractice you have to wait for students to log in. Also, students in a cyber-school environment could be home by themselves (although the SLPs commented that they were not supposed to be), with no one answering the phone.

Three of SLP interviewees discussed the ethics, confidentiality, and/or privacy of telepractice in speechlanguage pathology in school settings. The consensus was that these factors must be considered before the initiation of programming. Comments included the need to adhere to ASHA guidelines; abide by the ASHA Code of Ethics; maintain compliance with the Health Insurance Portability and Accountability Act (HIPPA); follow IEPs and IEP accommodations; consider the least restrictive environment; and employ informed consent for telepractice. One SLP cautioned against using Skype or other web conferencing programs that are not HIPPA compliant, and another SLP was concerned that conversations could be less confidential since she may not know who is in the room at the time in the remote location. (This was the same SLP who recommended a designated spot for telepractice in the school building.) Only one SLP mentioned licensure, such that telepractice should be provided by a licensed SLP. One SLP mentioned supervision explaining that supervisors can be highly supportive, but "it's not like doing it." There were no comments spontaneously generated about reimbursement for telepractice. When questioned, none of the therapists knew if their telepractice services were reimbursed by Medical Assistance or special funding sources. They were, however, aware that school entities did pay for the speech therapy services they provided.

The SLPs were directly questioned to discern if they felt there were particular types of students who would not be good candidates for telepractice services. Student candidacy is included as a barrier due to the experiences and concerns described by these SLPS, and their reported need for guidance and research in this area. Four of the SLPs expressed concerns about providing telepractice services to students with behavioral needs. They talked about needing to adjust to behavior problems but also to be proactive so as not to lose the students' attention. Sometimes the students did not use the microphones and at other times they would not interact. If the E-helper or assistant did not work on changing or shaping behaviors then further adjustments had to be made, such as encouraging typing. Thoughts were shared about some students getting bored and that these children may be better suited for in-person therapy. Behaviors in young children may be difficult to discern via telepractice, (e.g., are they not paying attention because of a disability or because they are just too young?) Another SLP questioned use of the "cyber environment" contending that it does not provide pragmatics practice (i.e., interacting with people in natural situations is not possible).

Other types of students for which telepractice may not be the best choice included complex and involved students, and those with sensory impairments such as hearing or vision. Two of the SLPs felt that telepractice would be difficult for students with "severe and profound" cognitive impairments. The lack of the in-person physical presence of the SLP was brought up again with reference to students with apraxia, voice, dysphagia, and those using augmentative devices because the physical "connection just isn't there." Other concerns focused on those students with severe psychological problems and those who are combative. One SLP thought students with ADHD would do well attending to computer programs, but found that this was not the case.

Another perceived weakness was that the "whole child' was not able to be considered. It was not as easy to discuss the student with others, nor could most of the SLPs talk directly with teachers, and there was no team teaching. Carryover was difficult because the SLP could not go into the classroom to help generalize 
skills. Specifically, students with fluency disorders were discussed in terms of needing "someone in the classroom" for carryover, but this could not be accomplished. These scenarios were discussed as detrimental to student growth. Comfort, exposure, and culture must also be considered to fully understand any student. For example, students may not work well in telepractice if they have not had much experience with computers. With time, however, this could change. One SLP cited students who, ostensibly due to their cultural background, did not have contact with computers and "cried for one month at every session, but after awhile" they grew to enjoy the sessions.

Dissatisfaction indicated by telepractice participants was included as a barrier due to its frequent reference as an obstacle to acceptance in the literature and the inherent relationship to the delivery and outcomes of the service itself. The SLPs reported cases of dissatisfaction from others, often before any involvement in telepractice. There were parents, teachers, and helpers who would not engage in the practice or presented obstacles such as not getting the students to therapy or to therapy on time. The SLPs experienced negative attitudes and heard comments from other educators such as "this is ridiculous." Case managers and other assistants vehemently expressed a lack of desire to be involved in telepractice. One case manager of a child did not like it at all, stated that in the first session, and refused to participate. "I expected great parental involvement, but that is not what I found," commented one SLP, while another offered that she missed not being in the building to discuss the students and "didn't realize how much you do that sort of thing." SLPs feel that others think the telepractice will not work and that some colleagues are against it. Attitudes make a difference in the success of the program, and at least one SLP felt that the telepractice approach "needs more support." Technology problems were previously discussed and these contributed to less than optimal sessions and thus dissatisfaction at times.

A quote summarizes this group of barriers and adds lack of research as an additional one, "I spent a couple weeks researching whatever I could find and there wasn't much." The participants felt that more research is needed on specific components of telepractice along with a need for mentors and supervisors who have actually provided telepractice services. Another insightful quote was that "we need more research so we do it correctly."

\section{TELEPRACTICE BENEFITS}

Access to speech-language pathology services ranked first on the list of benefits espoused by each individual SLP interviewed about telepractice in schools. Telepractice made service available to students who would not have received service otherwise or in lesser amounts. In two scenarios, the telepractice services eased the caseload burdens of onsite SLPs. Additional observations germane to this topic were that remote or rural schools could not obtain or keep SLP services; special education teachers would provide speechlanguage services under an educational certification variance; and that there was a need for quality service. The SLP who had provided telepractice services longer than the others felt that she could deliver telepractice services comparable to those provided in-person in schools, for just about every student. Altogether the telepractice distance format, according to these SLP respondents, provided "access to services that they [students] wouldn't have otherwise had," and "there is a need and I feel that this is a good quality format."

The SLPs discussed direct benefits for students: individualized programming, delivery options for students, access to specialists, and increased learning for students. In each of these areas only one or two SLPS contributed comments. Under the theme of individualized programming, it was felt that students can handle the specifics of the technology sessions themselves and are mostly independent. Another respondent stated "it's extremely intense and personal when it's just the two of you." One SLP commented that while there are advantages to both individual and group therapy, the pairing of two students for telepractice resulted in increased motivation, with students learning from one another (especially those engaging in articulation practice). Therapists' time can be scheduled to work with students in many locations throughout the day, providing delivery options and scheduling alternatives.

For students acquiring a second language, telepractice can offer a "huge benefit in native language and quality" by providing access to the specialized services of a bilingual SLP. Telepractice provided increased amounts of service, or services that students would not otherwise receive. Therefore, for some students, no progress could have occurred without access to telepractice. According to two of the five SLPs, when students receive the needed basic skills and services they were previously lacking, they benefit from increased access, programming options, and learning.

The SLPs felt that telepractice delivery increased learning for the students by eliciting more responses. Telepractice therefore "accelerates improvements," is conducted at a "faster pace," and leads to more rapid student progress and dismissals from therapy. The telepractice format helps students understand that the SLP cannot be with them all the time, and perhaps recognizing the value of their time in therapy, might work more intensively.

Lending credence to how telepractice assists student progress were comments about the use of video to document baseline and progress and excerpts of sessions, and that being able to send the students practice materials allows them to practice more. One 
SLP stated that "I can prove that it works because I have the data to show they make progress." But another SLP added a cautionary note about needing more research to substantiate the hope that the students were getting services as before. Student progress via telepractice was discussed by all interviewees, although the majority of the SLPs were hesitant to comment on the effectiveness of telepractice for students without research to substantiate their perceptions.

A positive feature that all five agreed upon was that this type of speech-language service delivery was easily accepted by the students since "we are in their world when we do telepractice." The SLPs indicated that the students were motivated by the computer and the technology. Technology has become a world in which children function daily. Even young children can work the mouse and log in and enjoy "the technology approach."

For some students, such as those on the autism spectrum, the use of computers can help them stay on task. One SLP thought that since handwriting is often difficult for these children, the act of typing was easier than writing. The headphones, another SLP believed, helped concentrate the sound directly into the ears which holds students' attention. Students are "locked in the lessons" and are hearing just the SLP so "distraction is minimal." Also, there is nothing else in the room to distract them so they can be more attentive.

Families and teachers discovered benefits from speech therapy services via telepractice. Mothers who typically would need to "pack up all of her kids, drive, entertain them all for 30 minutes while one gets therapy, then travel home," found that telepractice was much easier. One mother commented that she was surprised at how quickly telepractice worked with her sons since her daughter had received traditional therapy for 5 years. Showing parents videos of their child's progress and excerpts of sessions was also found to be advantageous. Parents and teachers can be more involved. It has been "well received by faculty and parents," one SLP explained, and teachers were amazed at the attention it commanded from students. People have expressed that "this is cool" and a great way to serve kids.

The SLPs realized many benefits for themselves from telepractice in speech-language pathology. Increased learning for the SLPs resulted from opportunities to discover the variety of programming in different schools, knowledge of "how they approach vocabulary or work with other SLPs," or "how administrations handle things like meetings or paperwork." One SLP remarked that she has acquired a great deal of information that she would not have otherwise learned. The service delivery can also be successful for learning and exchanging information for bilingual services; an increasingly needed specialized service. The ability to work with specialists benefitted the bilingual and monolingual SLPs alike as they learned from one another, with some SLPs learning Spanish while all professionals focused on helping students. Thus, collaboration with others is possible and helpful; the ability to "work with others and learn from students and a variety of staff" is a highly valued benefit to SLPs and to students. Travel related advantages were discussed by two of the five interviewed SLPs. Not having to travel to provide service to schools in rural or remote areas was noted by one SLP. Another SLP provided a noteworthy statement on the topic of travel: "I can move 120 miles in 45 seconds."

Finally, an immense advantage of telepractice programming is that of easing the shortage of SLPs, a benefit for everyone needing, trying to obtain, or providing speech-language pathology services. All of the therapists discussed the shortage either directly or through answers to other questions. They noted that there is a scarcity of qualified SLPs to provide the necessary services, in so many separate locations, and to so many diverse and needy students. Telepractice helps those schools that cannot find or retain SLPs, and in which students go year after year without service. One SLP remarked, "This is a great advantage to schools and students who struggle to get services."

However, the SLPs felt that schools, particularly the administrators, need to give telepractice a chance and greater support. For example, the schools, faculty and staff, need to notify the SLPs about school outings or other occasions that would interfere with treatment time. The consensus was that SLPs "can't do it ourselves." Support in terms of time, technology, and willingness are paramount. The barriers and benefits mentioned by the interviewed SLPs are displayed in Table 2.
Table 2 
Telepractice Barriers and Benefits

\begin{tabular}{|ll|}
\hline Barriers & Benefits \\
\hline Technology failures & - Access to SLP services \\
- Lack of training & - Individualized \\
- Lack of procedures & programming \\
- Nature of the & - Service delivery \\
environment & options \\
- Lack of physical & - Access to specialists \\
contact & - Increased learning \\
Establishing & - Acceptance by \\
therapeutic & students \\
relationships & - Collaboration \\
Ethical concerns & - Benefits for families \\
Student candidacy & and schools \\
Dissatisfaction & - Benefits for the SLP \\
- Lack of research & - Ease the shortage of \\
& SLPs \\
\hline
\end{tabular}

\section{REASONS FOR ACCEPTANCE AND USE OF TELEPRACTICE}

According to the five SLPs interviewed, the majority of fellow speech-language pathologists have concerns about telepractice. These concerns vary from the "fear of the unknown" and the "what if's...," to the specifics of the "how to's..." The SLPs experienced in telepractice feel that "some [SLPs] come with negative attitudes." SLPs unfamiliar with this form of service delivery express a desire for knowledge about "the technicality of telepractice" and specifically want to know how to arrange lessons, schedules, and materials. Three of the interviewees shared as follows: "first you struggle and it takes awhile," but "you can become confident;" "figuring it out was labor intensive;" and "now I know which materials are good for therapy." Each had to learn how to manipulate materials for telepractice. Three needed to develop PowerPoint or other materials, or learn which games, items, or stories were good for a particular type of communication disorder. One SLP was disappointed to not have any monies for materials. It took extra time, at first, to learn or create materials.

Another area of concern was the need to learn more about the nuances of the telepractice environment. "Communication involves more than sight and hearing," commented one SLP, but at present, [we] "don't know enough about it." She felt that it is necessary to develop telepractice but did not feel it would "ever be as functional."

Information about effective client selection was also felt to be lacking. For example, "I just don't know if the [severe profound, AAC] population would be the easiest or most effective to work with telepractice." They expressed the need to have others involved to provide behavioral intervention with certain students. Again, the need for more research was reiterated.

The SLPs expressed personal views on what they felt about providing services via telepractice to school populations. All five indicated positive degrees of satisfaction and professional growth. Comments ranged from "I love it!" to it was a "great experience," but also "it would not be my choice to do it all day." Four of the five reflected back on the lack of training they were given prior to implementing telepractice and how that impacts satisfaction levels. Other individual remarks included, "I have learned a lot," and it was something peers had not done, and "I was bringing something to something brand new." Still, one SLP found that she "felt challenged by going where so few have gone before" and indicated that she did not have answers about telepractice because it has not been well researched so she was "doing the best she could with something new." With regard to confidence, they all expressed increased self-confidence in their use of telepractice over time. Two SLPs expressed feeling "really confident," and one added it was "easy for me." They each added caveats concerning the evolving nature of telepractice, such as: "I have found good things [materials] and saved [them] in favorites;" "as technology improves issues will be resolved and telepractice will improve;" to attributing a lack of confidence to "having nothing to compare it to." One hoped her students were getting service like "face-to-face, but cannot say because it hasn't been researched well." Another felt that there was "no difference in the quality of my treatment." The overall sense was one of increasing satisfaction and confidence.

All five SLPs commented about the professional growth they experienced from providing telepractice services. Here the commentary revealed the ability to take on a challenge, broaden one's horizons, understand and run equipment, explore a great opportunity, and feel that one can handle any area that is presented. Other expressions on this topic were "I have had huge professional growth," "we want to be cutting edge," and "it's going to happen anyway, so let's prepare for this." Other positives expressed about telepractice service delivery were ease in scheduling ("I work from home"), family benefits ("home for children"), and travel ("was driving 70-100 miles a day," you can "sign in and have at it!"). 


\section{SUGgestions TO ResOlVE TELEPRACTICE PROFESSIONAL ISSUES}

The SLPs spontaneously offered suggestions to resolve the professional issues pertinent to telepractice in speech-language pathology. Solutions that the SLPS discovered to overcome technology failures included the use of high end software; use of two Internet browsers; an available second computer; virus protection; available technical support; and learning how to trouble shoot so that [you] "have a good handle on that so you can fix things." Additionally, one SLP revealed that she keeps a back up battery in case the electricity shuts off. Knowing ways to improve the sound, such as how to "make [the] echo softer and turn the volume down," were also recommended.

Along with these suggestions for handling technology failures, the SLPs had ideas on the requisite training needs for telepractice. They explained it was necessary to have advance knowledge of basic computer skills and the software system. It is important to possess knowledge of the video system, log in system, how microphones and speakers work, and how to control the screen size was suggested. The therapist should be able to engage in trouble shooting, due to the occurrence of technology failures. One respondent commented that "tech savvy people can do this; if an online therapist, it's a given that you are tech able." All interviewees felt that technology problems would lessen in the future as the technology improved.

SLPs expressed that training for themselves and their E-helpers or assistants should be completed prior to beginning any telepractice program. The five SLPS believed that all practitioners and assistants should be provided with training on the technological aspects of telepractice such as the particular computer system and settings, and understand the connections, software, and equipment. One participant commented that everyone should be "extremely comfortable with the technology." Additional technology specifics included: knowing how to operate cameras, computer games, shared windows, student settings, and how to reboot, re-enter the system, log on, and optimize home computer settings. It is important to know how to fix things or quickly connect with technical support. One SLP suggested that technology support should be available for any issues because you "need that level of support or [you will] spend time fixing things and not working with the child." Another interviewee stated, technology support "would be vital."

The SLPs also recommended that training of E-helpers include specifics on how to follow the schedule to get students to and from therapy sessions, how to redirect students and provide behavioral interventions, and how to do assigned homework. One SLP stated that specific telepractice job descriptions and E-helper job responsibilities should be established and shared with all participants. Finally, the SLPs agreed on the need to assign an experienced SLP to telepractice who was willing to train and keep up to date with effective speechlanguage pathology therapy strategies.

Prior to starting any telepractice program a list of procedures should include: train people first; "have materials ready;" be familiar with the students' evaluation reports and IEPs ahead of time; "be prepared before treatment;" "know what is first, second, third, fourth;" have paperwork, consent forms, explanations of equipment, explanations of how the process works, explanation of responsibilities of parents, E-helpers, school; and complete a "tech check to make sure everything is working prior to first real session." The SLPs took into account the need to "follow the IEP as written" but also to create "a curriculum for a different method of presentation" that should be "in place prior to telepractice starting." Other suggestions were to know "how games work, how the report generating system works, and how to document." The SLPs felt that those contemplating telepractice should understand that time must be allocated for the SLPs to become accustomed to telepractice equipment, materials, and scheduling, and for opportunities to work with peers in a peer network. Additionally, with regard to the present state of telepractice knowledge, it would be helpful to find SLPs who are not afraid of or reserved about the use of technology and the materials to be utilized. One SLP remarked that more research is needed on specific technology and procedures for telepractice in speechlanguage pathology.

Scheduling was a major procedural hurdle for which the SLPs felt that practitioners new to telepractice needed to know and think about ahead of time in order to proactively preplan preparations and arrangements for maximum student benefit. To resolve scheduling conflicts, learning to elicit help from others in the school or the home took delicate handling but was a necessary aspect of the job. Events such as fire drills, noisy rooms, and siblings or others in the environment were unexpected but not uncommon. One case in point was the fire drill where the SLP was in a building she had to vacate; however, she could not abruptly leave the student's telepractice session without assistance on the students' side. She remarked how this actual occurrence demonstrates the importance of having procedures in place. Another SLP talked about using the phone when technology failed, but did not feel this facilitated adequate treatment. The SLPs quickly learned to cope by explaining procedures carefully to students and others ahead of actual lessons.

Suggestions were offered by the SLPs on how to handle the static or distant nature of the telepractice environment. The therapists need to be "really fun for the kids" and not allow "any dead air time." When technical difficulties arise, the therapists must "pretend that everything is going well," and multitask, such as typing to the technical support person while "still engaging a child 
and not showing any signs of stress." To accommodate for the lack of physical contact, the therapists revealed that you must "get better at your descriptions and explanations," "use visuals to show how to move the articulators," and ask assistants or others to "help with the physical work - to help the kid touch or bite [his] lip."

Tips for establishing relationships with online partners included: call, email, have older students or E-helpers write down what to work on, or send speech practice postcards to the homes. Good management of telepractice sessions and ultimate success depends upon good relationships with those participating in the telepractice programs.

With regard to the topic of dissatisfaction from others, the SLPs had particular characteristics in mind for those participating in telepractice. They suggested that a "good healthy attitude" toward telepractice is key since the "success of session or program depends on the therapist's mindset." Anyone attempting telepractice, cautioned these veteran SLPs, should be patient, like kids, enjoy what they are doing, and be open minded. Flexibility and willingness to change were characteristics recommended by the SLPs. One SLP summed this up with the statement: "Be flexible; if everything has to be perfect than you can't do the job." Another remarked that there is a "fascination and terror about this" among professionals. Because there will be SLPs who are inherently uncomfortable with technology, these individuals will need more time and encouragement to train and become familiar with the telepractice approach to speech-language therapy.

The idea of mentorship was a resolute and recurring suggestion. Finding a SLP colleague experienced and comfortable with providing telepractice services, and willing to share experiences, how to do things, and train others was discussed as paramount to success. It was suggested that having telepractice presented within the discipline of speech-language pathology and having someone to work with would help support the SLPs and be "vital to grow [telepractice] well." Research was another resounding suggestion. Investigation into the various components of telepractice is essential to help SLPs understand, use, and accept this form of service delivery. Two of the SLPs in this group of interviewees had personally looked into research on telepractice procedures, student selection candidacy, and efficacy and did not find sufficient information to help support them in implementing telepractice in speech-language pathology.

\section{DISCUSSION}

The viewpoints expressed by the interviewed group of SLPs experienced in school-based telepractice were found to be similar across themes but with variability within a given theme and dissimilar telepractice experiences.

The first major theme was a list of barriers that was similar among the SLPs in this study and to those reported in the telemedicine, telehealth, and telepractice literature. For example, these individuals cited difficulties with technology failures, procedural uncertainties, environmental constraints, and lack of information about student candidacy and therapeutic effectiveness. The telepractice environment appeared to add another layer to the intricacies of itinerant work, such as solving additional scheduling and relationship problems. The SLPs indicated uncertainty regarding student candidacy for telepractice on such variables of attention, age, behavior, sensory impairments, cognitive abilities, and cultural differences. When compared to previous research, the responses from this present group of interviewed SLPs appeared to indicate more challenges from the delivery of day to day therapy via telepractice. Barriers listed frequently in the telepractice literature regarding regulations, licensure, credentials, supervision, and reimbursement were not issues for the interviewed SLPs. This may indicate an evolving understanding and acceptance of telepractice that heretofore has not been documented in the literature. However, the limited sample of interviewees and work settings may also be contributing factors.

The next theme involved the perceived benefits from telepractice. In accordance with the benefits found in the literature, the SLPs in this study reported access to speech-language pathology services as the greatest advantage to the population of students served. Increased access benefits the students, families, teachers, and SLPs. First, students exposed to technology on a daily basis readily accept and easily use technology, making telepractice a beneficial model of service delivery. Students benefit by increased access and collaboration with specialists. Telepractice makes individualized programming and convenient delivery options more accessible. Increased access to therapy also benefits families, teachers, and SLPs in terms of communication with one another, speed of service delivery, and decreased travel. The interviewees conveyed that services accessed through telepractice helped lessen the caseload burdens of other SLPs and eased the present shortage of these professionals within the speech-language pathology field.

The third theme generated from the qualitative interviews with the SLPs dealt with their beliefs regarding reasons for acceptance or use of telepractice. Attitude toward telepractice was a key factor. Some SLPs may think online therapy is too hard or that it is a simple matter of "logging on to the computer and typing." The unknown 
was "scary initially" and with telepractice there was "nothing to compare it to," according to some members of this group of SLPs. As with anything new, there was a learning curve. However, with time and experience the SLPs found that telepractice could be adapted and used to great advantage for themselves and their students. The SLPs reported personal satisfaction and growing confidence in their knowledge and skills through providing speech-language support services via telepractice. The SLPs felt that all those involved in telepractice "must be willing to embrace it."

The final theme emerged from the spontaneously generated suggestions that the SLPs offered. Their solutions for overcoming technology and procedural challenges may serve as a starting point for others planning a telepractice program for school students. Their suggestions about establishing telepractice relationships and tips for material and student management could assist with quality implementation processes. They were clear that support, in the form of mentorship and administrative backing, is essential through all stages of telepractice programming. A SLP mentor would help dispel fears by providing information on steps to follow and sharing of actual experiences. An available mentor could assist with unique situations that arise.

The SLPs' requests for more research concerning telepractice procedures, guidelines, student candidacy, and therapeutic effectiveness suggest future telepractice studies.

The study's qualitative findings, confined as they are to 5 SLPs in one northeastern state, cannot be generalized to all SLPs in other telepractice locations. However, the qualitative interviews shed light on encountered experiences and held beliefs toward the use of telepractice in speech-language pathology. As such, it helps propel the discussion forward for those who are contemplating or beginning to use this form of service delivery to reach clientele. Only with continued gathering of pieces of information, such as provided by this research, can the field have informed discussions for capacity building and decision making about how best to use telepractice for communicatively impaired clients.

\section{ACKNOWLEDGEMENT}

This work was generated as part of an Applied Dissertation, Nova Southeastern University, North Miami Beach, FL. 


\section{REFERENCES}

1. Alverson, D., Holtz, B., D’lorio, J., DeVany, M., Simmons, S., \& Poropatich, R. K. (2008). One size doesn't fit all: Bringing telehealth services to special populations. Telemedicine and e-Health, 14, 957- 963. doi: 10.1089/ tmj.2008.0115

2. American Speech-Language-Hearing Association. (2002). Survey report on telepractice use among audiologists and speech-language pathologists. Retrieved from American Speech-Language-Hearing Association website: http:// www.asha.org/uploadedFiles/practice/telepractice/ SurveyofTelepractice.pdf

3. American Speech-Language-Hearing Association. (2005a). Knowledge and Skills Needed by SpeechLanguage Pathologists Providing Clinical Services via Telepractice [Knowledge and Skills]. doi: 10.1044/policy. KS2005-00077. Retrieved from American SpeechLanguage-Hearing Association website: http://www. asha.org/policy/KS2005-00077.htm

4. American Speech-Language-Hearing Association. (2005b). Speech-Language Pathologists Providing Clinical Services via Telepractice: Position Statement [Position Statement]. doi: 10.1044/policy.PS2005-00116. Retrieved from American Speech-Language-Hearing Association website: http://www.asha.org/docs/html/ PS2005-00116.html

5. American Speech-Language-Hearing Association. (2005c). Speech-Language Pathologists Providing Clinical Services via Telepractice: Technical Report [Technical Report]. doi: 10.1044/policy.TR2005-00152. Retrieved from American Speech-Language-Hearing Association website: http://www.asha.org/policy/TR2005-00152.htm

6. American Speech-Language-Hearing Association. (2010). Professional Issues in Telepractice for Speech-Language Pathologists [Professional Issues Statement]. doi:10.1044/ policy.PI2010-00315. Retrieved from American SpeechLanguage-Hearing Association website: http://www. asha.org/policy/PI2010-00315.htm

7. Bernard, H. R., \& Ryan, G. W. (2010). Analyzing Qualitative Data Systematic Approaches. Retrieved from http://www. sagepub.com/upm-data/30485_Chapter3.pdf

8. Brennan, D., \& Barker, L. M. (2008). Human factors in the development and implementation of telerehabilitation systems. Journal of Telemedicine and Telecare, 14, 5558. doi: 10.1258/jtt.2007.007040

9. Bulik, R. J. (2008). Human factors in primary care telemedicine encounters. Journal of Telemedicine and Telecare, 14, 169-172. doi: 10.1258/jtt.2007.007041

10. Bureau of Labor and Statistics. United States Department of Labor (2010-2011). Occupational Outlook Handbook, 2010-2011 Edition, Speech-Language Pathologists. Retrieved from http://www.bls.gov/oco/ocos099.htm

11. Castrogiovanni, A. (2008). Incidence and prevalence of communication disorders and hearing loss in children - 2008 edition. American Speech-Language-Hearing Association. Retrieved from http://www.asha.org/ research/reports/children.htm

12. Creswell, J. W. (2008). Educational research: Planning, conducting, and evaluating quantitative and qualitative research (3rd ed.). Upper Saddle River, NJ: Pearson Publishing.

13. Creswell, J. W., \& Plano Clark, V. L. (2011). Designing and conducting mixed methods research. Thousand Oaks, CA: Sage Publications, Inc.
14. Dunkley, C., Pattie, L., Wilson, L., \& McAllister, L. (2010). A comparison of rural speech-language pathologists' and residents' access to and attitudes towards the use of technology for speech-language pathology service delivery. International Journal of Speech-Language Pathology, 12, 333-343. doi: 10.3109/17549500903456607

15. Fink, A. (2003). The survey kit (2nd ed.).Thousand Oaks, CA: Sage Publications.

16. Forducey, P. (2006, August). Speech telepractice program expands options for rural Oklahoma schools. The ASHA Leader Online. Retrieved from http://www.asha.org/ Publications/leader/2006/060815/060815f.htm

17. Grogan-Johnson, S., Alvares, R., Taylor, J., Gabel, R., Rowan, L., \& Allendar, N. (2009). Providing telepractice services to children in rural Ohio - year 2. Retrieved from http://www.ehhs.kent.edu/telepractice/research.htm

18. Hjelm, N. M. (2005). Benefits and drawbacks of telemedicine. Journal of Telemedicine and Telecare, 11, 60-69.

19. Juenger, J. M. (2009a, July). Telepractice in speech/ language: How to get there from here. Session presented at the American Speech-Language-Hearing Association (ASHA) Schools Conference, Kansas City, MS.

20. Juenger, J. M. (2009b, September 22). Telepractice in the schools. The ASHA Leader, 14(12), 20-21.

21. Mashima, P. A., \& Doarn, C. R., (2008). Overview of telehealth activities in speech-language pathology. Telemedicine and e-Health, 14, 1101-1117. doi: 10.1089/ tmj.2008.0080

22. Morton, J., Mullin, P., \& Biemer, P. (2008). Using reinterview and reconciliation methods to design and evaluate survey questions. Survey Research Methods, 2(2), 75-82.

23. Pennsylvania Department of Education. (2008). Public Schools Professional Personnel Statistics. Retrieved from http://www.education.state.pa.us/portal/server.pt/ community/data_and_statistics/7202

24. Polovoy, C. (2008, July 15). Telepractice in schools helps address personnel shortages. The ASHA Leader, 13(9), 22-24.

25. Scheideman-Miller, C., Clark, P. G., Moorad, A., Post, M. L., Hodge, B. G., \& Smeltzer, S. (2003). Efficacy and sustainability of a telerehabilitation program. Hawail International Conference of System Sciences, 6, 1-11. doi: 10.1109/HICSS.2003.1174380

26. Scheideman-Miller, C., Clark, P. G., Smeltzer, S. S., Cloud, C., Carpenter, J., Hodge, B., \& Prouty, D. (2002). Two year results of a pilot study delivering speech therapy to students in a rural Oklahoma school via telemedicine. Retrieved from http://www.hicss.hawaii.edu/HICSS_35/ HICSSpapers/PDFdocuments/HCTMD06.pdf

27. Schwartz, H. \& K. Drager. (2008). Training and knowledge of autism among speech-language pathologists: A survey. Journal of Speech-Language-Hearing in Schools, 39, 66-77.

28. Whitten, P., \& Holtz, B. (2008a). A series of papers for those yearning to propel telehealth to new heights. Telemedicine and e-Health, 14, 952-956. doi: 10.1089/ tmj.2008.0129

29. Whitten, P., \& Holtz, B. (2008b). Provider utilization of telemedicine: The elephant in the room. Telemedicine and e-Health, 14, 995-997. doi: 10.1089/tmj.2008.0126 
